\title{
Author Correction: Senescent cells promote tissue NAD+ decline during ageing via the activation of $\mathrm{CD}^{2} 8^{+}$macrophages
}

Anthony J. Covarrubias (1D), Abhijit Kale (1), Rosalba Perrone (1D), Jose Alberto Lopez-Dominguez (1), Angela Oliveira Pisco, Herbert G. Kasler, Mark S. Schmidt @ , Indra Heckenbach, Ryan Kwok (D), Christopher D. Wiley, Hoi-Shan Wong (D, Eddy Gibbs, Shankar S. Iyer, Nathan Basisty, Qiuxia Wu, Ik-Jung Kim, Elena Silva, Kaitlyn Vitangcol, Kyong-Oh Shin, Yong-Moon Lee (1D, Rebeccah Riley, Issam Ben-Sahra (1), Melanie Ott, Birgit Schilling $\mathbb{D}$, Morten Scheibye-Knudsen, Katsuhiko Ishihara (D), Stephen R. Quake, John Newman (D), Charles Brenner (D), Judith Campisi and Eric Verdin (1)

Correction to: Nature Metabolism https://doi.org/10.1038/s42255-020-00305-3, published online 16 November 2020.

In the version of this article initially published, in Fig. 3e, a data point was missing on the M1 WT bar in the ADPR graph, and two extraneous data points were present above the M1 Cd38 KO bar in the ADP graph. In addition, in Fig. 7l, three asterisks indicating statistical significance were missing above the rightmost LPS bar in the NAM graph. Finally, in the last paragraph of the discussion, a description and citation of a related manuscript published in the same issue of Nature Metabolism had been inadvertently omitted. The errors have been corrected in the HTML and PDF versions of the article. 


\section{Original}
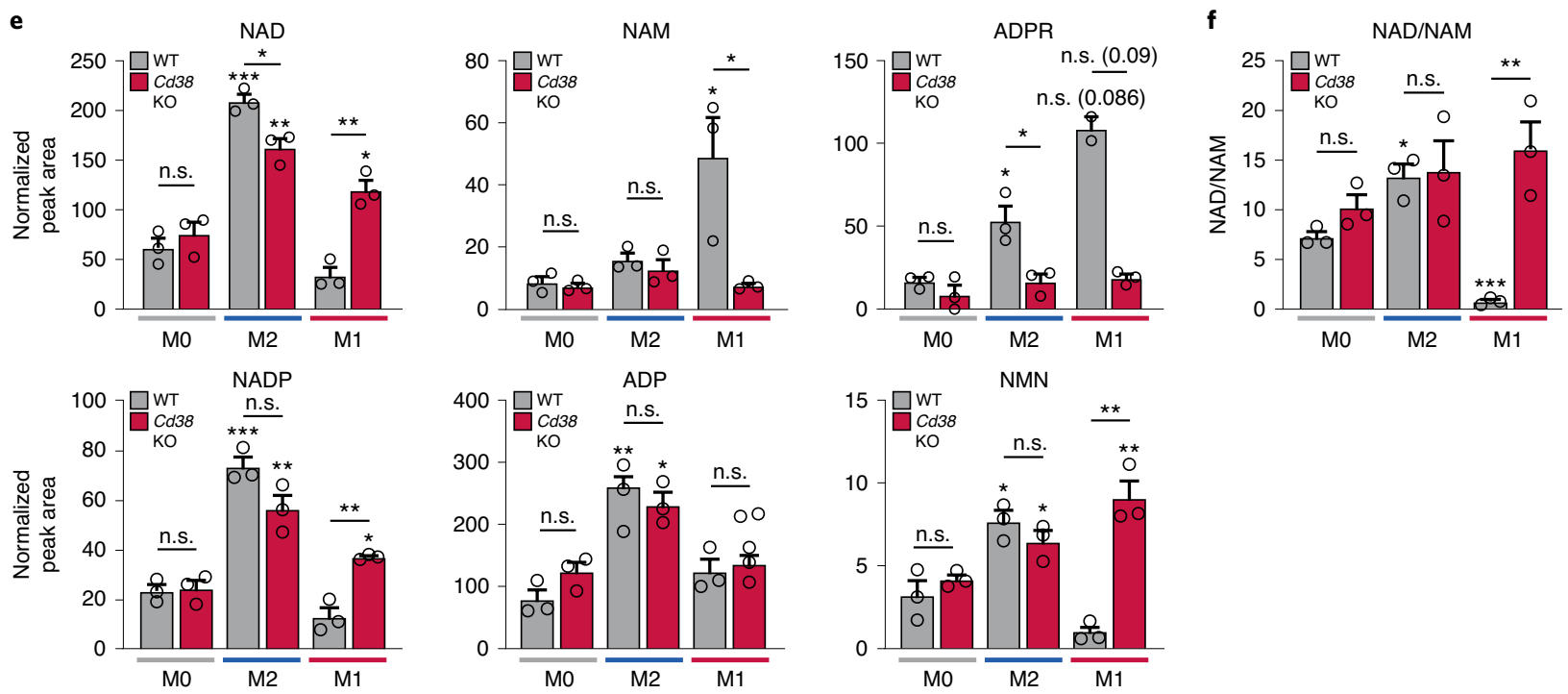

Corrected
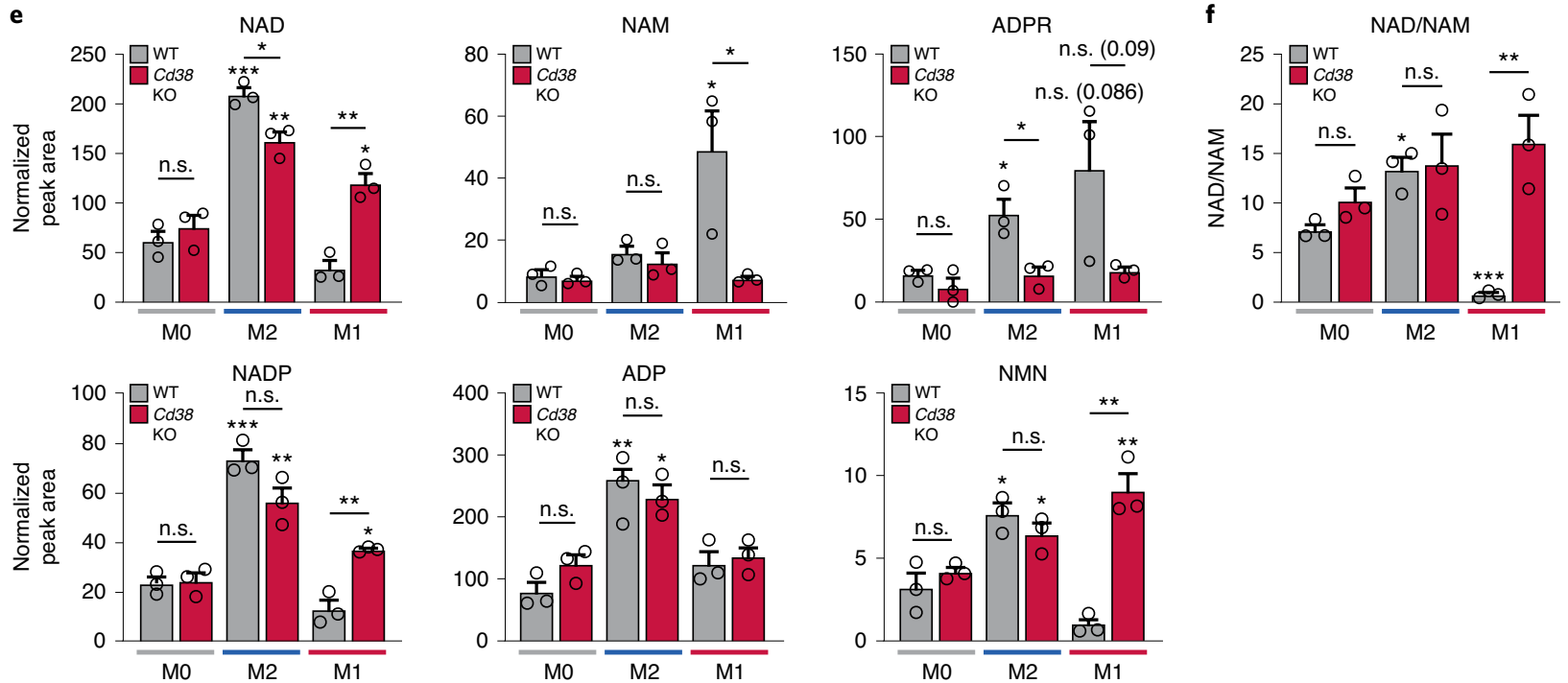

Fig. 3 | Original and corrected.

Published online: 10 December 2020

https://doi.org/10.1038/s42255-020-00328-w

(c) The Author(s), under exclusive licence to Springer Nature Limited 2020 